Methods Data between 1994 and 2003 helped to determine evolution and prediction of the disease and were given by the CRNT, this registry is covering the north of Tunisia then half of the Tunisian population. The data of incidence, by age bracket of 5 years, were planned for 4 periods 2004-2008; 2009-2013; 2014-2018; 2019-2024. For the analysis we used a model of type Bayésien agetroop. The implementation of this analysis was realised by a sampling of Gibbs by means of the software WinBUGS.

Result Between 1994 and 2003, we observed negative annual average spleen of standardised incidence evolution in men and women $(-3.3 \%$ vs $2.7 \%)$ also for the standardised incidences which showed a rather important decline $(26.4 \%$ at the man and $-22.3 \%$ at the woman). Between periods 1994-1998 and 2019-2024, at the man the number of annual average case could decrease in $36 \%$. At the woman, the number of annual average case could remain stable, the specific rates according to the age increase from the age bracket 65 to 69 but decrease rather sharply at the child's and the adults whose age is 65-year-old subordinate. Then an important decrease of $70 \%$ in men and $45 \%$ in women was observed. NPC acknowledged a favourable evolution from 1994 to 2003 probably due to a better socioeconomic level. If this tendency is maintained, it could be an interesting area of research.

\section{SP3-5 INCIDENCE OF BREAST CANCER IN NORTHERN TUNISIA: TREND AND PROJECTION INTO 2024}

doi:10.1136/jech.2011.1429760.5

${ }^{1} \mathrm{M}$ B Abdallah, ${ }^{1}$ W H B Ayoub, ${ }^{2} \mathrm{H}$ Rais, ${ }^{*} \mathrm{~S}$ Zehani, ${ }^{3} \mathrm{H}$ Hsairi, ${ }^{3} \mathrm{~N}$ Achour. ${ }^{1}$ Department of Epidemiology and Biostatistics, Salah Azeiz Institute of oncology, Tunis, Tunisia; ${ }^{2}$ Medical Oncology Department, Salah Azeiz Institute of oncology, Tunis, Tunisia; ${ }^{3}$ National Institute of Public Health, Tunis, Tunisia

Breast cancer is the most frequent cancer localisation in Tunisian women. With ageing of population, combined to a generation effect, it is very likely that we will see in near future an important rise in breast cancer incidence. Also all the Tunisian data have always shown a high rate of young patients (ages below 35 years) around $11 \%$. This study is designed to establish a forecast of the level of the incidence and of a numbers of cases of breast cancer until 2024 in Northern Tunisia. We also try to foresee the evolution of the percentage of young women.

Methods Data given by the Cancer Registry of Northern Tunisia (CRNT) from 1994 to 2003 are used as a baseline for further prediction. This cancer register is covering half of the Tunisian population. Data of the incidence have estimated for the periods 2004-2008; 2009-2013; 2014-2018; 2019-2024. Predictions were based on a Bayesian Age-Cohort model. The implementation of this trial has been carried out by sampling after Gibbs method using WinBugs software.

Results The number of cases is growing continuously over the four periods. Thus, in 2019-2024, nearly 2000 cases/year are expected in the Northern part of the country. The standardised incidence will grow from 21.6 cases/100 000 women in 1994-1998 to 46.4 cases/ 100000 women in 2019-2024, an increase of $80 \%$. Until the age of 59 the specific rates par age rise moderately, beyond we can observe acceleration. Finally the projection allows a follow-up of the percentage of young women $<35$ years in step with the periods. The ageing of the population and the cohort effect let us prevue a clear tendency to fall.

Conclusion The evolution of the percentage of young women show that the modification of the ages pyramid of the general population paired to a cohort effect (the future generations will have a higher risk), will lead to a lowering of this percentage over years. Thus it is very likely that we can't keep the genetic hypothesis (Tunisian women would have a higher risk due to genetic state).

\section{SP3-6 ADOLESCENT SEXUAL BEHAVIOUR AND HIV/AIDS IN ETHIOPIA: EPIDEMIOLOGICAL PERSPECTIVES}

doi:10.1136/jech.2011.1429760.6

A S Susuman. * University of the Western Cape, Cape Town, South Africa

Introduction Adolescents will be the influential force behind economic prosperity in the future of Ethiopia. Ethiopian adolescent communities today face many health-related challenges, and their lives vary considerably from those of their parents, grandparents and other relatives. A number of behaviours lead to increased risk of getting HIV/AIDS, in particular unprotected sexual intercourse and multiple sexual partners.

Methods and Materials Drawing on data from the Ethiopia Demographic and Health Survey (DHS) 2005, this study focused on the latest information about Ethiopian's adolescent people, age 15-24. The DHS collected data from more than 10000 women and men nationwide including 5813 females and 2399 males in the age group 15-24 years. Regression modes were developed separately for males aged 15-24 years and females aged 15-24 years.

Results Fertility and mortality rates fell, but were still subject to short-term variation. Average mortality was 8.2 per 1000 person years, consistent with AIDS-related deaths.

Conclusion A new local hospital in 2005 may have contributed to falls in overall illness. Adolescent sexual behaviour and HIV/AIDS remains a challenge and an area for healthcare providers to focus on. The Ethiopian adolescent population has undergone complex changes during a single generation. This research is designed to help program managers, community leaders and organisations working with adolescence to understand some of the epidemiological challenges.

\section{SP3-7 HYPERTENSION REPERCUSSION ON GENERAL MORTALITY IN A HISPANIC POPULATION}

doi:10.1136/jech.2011.1429760.7

M A L de la Vega,* S G Briceño, E R Silva, J J Villasmil. Instituto Regional de Investigación y Estudios de Enfermedades cardiovasculares, Maracaibo-Estado Zulia, Venezuela

Objective To determine the repercussion of Hypertension $(\mathrm{H})$ on general mortality in Venezuela during the period: 2003-2007.

Methods Data obtained of Health Ministry, surged of the death certificates, selecting all codes associated with $\mathrm{H}$ mortality and heart diseases mortality (HD) [10th Review]. The HD and H mortality rates were calculated for each studied year and were expressed as the mean of the period. The repercussion of $\mathrm{H}$ mortality on $\mathrm{HD}$ mortality and general mortality was estimated using the proportionate rates.

Results The general mean $\mathrm{H}$ mortality rates were 32.15 , 31.91 and 32.93 per 100000 populations for all subjects, males and females respectively. The age-adjusted $\mathrm{H}$ mortality rates for each studied year were: for males 673.66, 612.76, 694.10, 609.3 and 448.89 per 100000 populations and for females, 842.82, 927.25, 836.29, 794.79 and 1090.61 per 100000 populations. The mean proportionate rate of $\mathrm{H}$ (all codes associated) on the general mortality was $7.05 \%$ and $\mathrm{H}$ mortality (I11-I13 codes only) on HD mortality was $24.92 \%$.

Conclusions $\mathrm{H}$ mortality show a high repercussion on both general and HD mortality in Venezuela. Females show a higher tendency to dye for $\mathrm{H}$. Non-systematic observations permit to think in the presence of underestimate values for the $\mathrm{H}$, besides the procedures used for the selection of the underlying cause of death, lead to the exclusion of pathologies with $\mathrm{H}$ ethiology, being probable that the true repercussion of $\mathrm{H}$ on general mortality be higher than the national mortality data permits to know. 